\title{
Influence of casein on flux and passage of serum proteins during microfiltration using polymeric spiral-wound membranes at $50^{\circ} \mathrm{C}^{1}$
}

\author{
Justyna Zulewska* and David M. Barbanot ${ }^{2}$ \\ ${ }^{*}$ Faculty of Food Sciences, University of Warmia and Mazury, Olsztyn, Poland 10-719 \\ †Cornell University Department of Food Science, Northeast Dairy Foods Research Center, Ithaca, NY 14853
}

\begin{abstract}
Raw milk (approximately 1,800 kg) was separated at $4^{\circ} \mathrm{C}$, pasteurized (at $72^{\circ} \mathrm{C}$ for $16 \mathrm{~s}$ ), and split into 2 batches. One batch $(620 \mathrm{~kg})$ was microfiltered (MF) using pilot-scale ceramic uniform transmembrane pressure Membralox membranes (model EP1940GL0.1 $\mu$ A, 0.1- $\mu$ m alumina; Pall Corp., East Hills, NY) to produce retentate and permeate. The permeate from the MF uniform transmembrane pressure was casein-free skim milk (CFSM). The CFSM was MF using polymeric spiral-wound (SW) membranes (model FG7838-OS0xS, $0.3 \mu \mathrm{m}$; Parker-Hannifin Corp., Process Advanced Filtration Division, Tell City, IN) at a concentration factor of $3 \times$ and temperature of $50^{\circ} \mathrm{C}$. Following the processing of CFSM, the second batch of skim milk $(1,105 \mathrm{~kg})$ was processed using the same polymeric membranes to determine how casein content in the feed material for MF with polymeric membranes affects the performance of the system. There was little resistance to passage of milk serum proteins (SP) through a 0.3$\mu \mathrm{m}$ polyvinylidene fluoride (PVDF) SW membrane at $50^{\circ} \mathrm{C}$ and no detectable increase in hydraulic resistance of the membrane when processing CFSM. Therefore, milk SP contributed little, if any, to fouling of the PVDF membrane. In contrast, when processing skim milk containing a normal concentration of casein, the flux was much lower than when processing CFSM (17.2 vs. $80.2 \mathrm{~kg} / \mathrm{m}^{2}$ per hour, respectively) and the removal of SP from skim milk with a single-pass $3 \times$ bleed-andfeed MF system was also much lower than from CFSM ( 35.2 vs. $59.5 \%$ removal, respectively). Thus, when processing skim milk with a PVDF SW membrane, casein was the major protein foulant that increased hydraulic resistance and reduced passage of SP through the membrane.
\end{abstract}

\footnotetext{
Received August 5, 2012.

Accepted October 20, 2012

${ }^{1}$ Use of names, names of ingredients, and identification of specific models of equipment is for scientific clarity and does not constitute any endorsement of product by authors, University of Warmia and Mazury, Cornell University, or the Northeast Dairy Foods Research Center.

${ }^{2}$ Corresponding author: dmb37@cornell.edu
}

Key words: microfiltration, fouling, polymeric membrane

\section{INTRODUCTION}

One of the main applications of microfiltration (MF) in the dairy industry is fractionation of casein micelles and serum proteins (SP) from skim milk (SM). Different membrane materials in different configurations can be used for this application. However, the composition and the functional properties of the final concentrated products of MF (i.e., micellar casein concentrate and SP concentrate) may differ depending on the performance of the membranes. Zulewska et al. (2009) studied the influence of different membrane characteristics on SP removal: ceramic uniform transmembrane pressure (UTP), ceramic graded permeability (GP), and spiralwound (SW) polyvinylidene fluoride (PVDF). Differences $(P<0.05)$ in SP removal between systems were detected, with polymeric SW membranes having the lowest SP removal (38.6, 61.0, and $64.4 \%$ for SW, GP, and UTP, respectively). What caused lower SP removal by polymeric SW membranes under the conditions used in the studies by Zulewska et al. (2009) and Beckman et al. (2010) compared with the SP removal observed for ceramic membranes in the study by Zulewska et al. (2009)? The separation of casein and SP by 0.1$\mu \mathrm{m}$ ceramic membranes relies on the selectivity of the membranes (Brans et al., 2004) and the lift on particles in the feed stream created by very high shear turbulent flow (Altmann and Ripperger, 1997), whereas separation of casein and SP with SW polymeric membranes depends more on the combination of properties of the membrane and the fouling layer. The fouling layer plays a larger role for polymeric membranes because crossflow velocity in polymeric systems is generally lower than for ceramic membrane systems and polymeric membranes adsorb milk components (van der Horst, 1995) onto their surface in addition to having concentration polarization-driven fouling compared with ceramic membranes. Individual whey proteins adsorb on to hydrophobic polymeric membranes and a direct relationship exists between protein adsorption, increase 
in membrane resistance, and protein rejection (van der Horst, 1995). As polymeric membrane pores are blocked, the layer of foulant material produces a higher total hydraulic resistance and a difference in solute rejection characteristics than the original membrane. This may be termed a dynamic membrane, which has lower permeability than the original filtration membrane (James et al., 2003).

Concentration polarization, fouling, and highpressure loss along the feed and the permeate channel height are the major issues during processing with polymeric SW membranes (Schwinge et al., 2004). The absolute feed and permeate channel height as well as the ratio between the feed and permeate channel height influence to a great extent the productivity of the SW module (Schwinge et al., 2004). At the ratio beyond the optimum (0.5 to 1$)$ both higher feed or permeate channel pressure decreases will lead to a flux reduction and lower productivity (van der Meer and van Dijk, 1997). Both concentration polarization and fouling diminish the permeation rate by increasing hydraulic resistance to permeate flow (Marcelo and Rizvi, 2009). Huisman et al. (2000) listed the physicochemical properties of the membrane, the hydrodynamic conditions of the process, and the feed solution as the main factors that have an effect on fouling. The hydrophobic nature of polymeric membranes causes protein adsorption to the membrane (Baruah et al., 2006), resulting in fouling. The degree of concentration polarization and fouling depends also on hydrodynamic conditions in cross-flow MF, whereas the permeate flux drags solutes toward the membrane the cross-flow induces particle back transport into the bulk feed solution (Huisman and Trägårdh, 1999). When the movement toward the membrane of solutes exceeds the rate of back transport, concentration polarization of that rejected solute occurs. The type of the feed material processed, especially the protein content, which has been characterized as the main foulant of the filtration membranes (Marshall et al., 1993), influence to a great extent performance of the membrane. Milk is a very complex feed solution containing different types of protein (i.e., caseins and SP) that can contribute to fouling in a different way, either by interacting with each other or with the membrane. Membrane fouling due to the protein-protein interactions results from buildup of the adsorbed protein layer that can change the sieving characteristics of the membrane (James et al., 2003). Protein-membrane interactions may cause pore plugging, pore narrowing, and solids deposition that lead to cake formation on the membrane surface (Belfort et al., 1994). The mechanism and strength of proteinmembrane interactions for different types of proteins may vary. Kelly and Zydney (1997) demonstrated that the protein structure, charge, and reactivity determine the rate and extent of fouling during microfiltration. Several studies have compared the behavior of different milk proteins during milk UF (Reihanian et al., 1983; Tong et al., 1988), but the effects of different classes of milk proteins can be different for UF and MF due to the differences in pore size of the selective layer of the 2 processes. Protein fouling in UF systems is determined largely by concentration polarization effects (Aimar and Sanchez, 1986; Aimar and Field, 1992). In contrast, protein fouling in MF is due primarily to the physical deposition of trace amounts of large protein aggregates on the membrane surface, which can cause very large flux declines even during the filtration of relatively pure and undenatured proteins in solution (Belfort et al., 1994). Previous studies of protein fouling during MF have generally focused on the behavior of a singlemodel protein (Meireles et al., 1991; Kelly et al., 1993; Tracey and Davis, 1994; Kelly and Zydney, 1995; Guell and Davis, 1996; Kelly and Zydney, 1997). Very little is known about fouling of polymeric MF membranes by milk proteins when SM is processed. Therefore, the objective of our research was to determine the influence of casein in the feed solution on performance of polymeric SW MF PVDF membranes. This was achieved by comparing the percentage of SP removal, rate of SP removal, flux and blockage of SP passage through the membrane during MF processing casein-free SM (CFSM) and SM with SW PVDF membranes at $50^{\circ} \mathrm{C}$.

\section{MATERIALS AND METHODS}

\section{Overall Experimental Design and Statistical Analysis}

Two feed solutions: SM and CFSM were processed with polymeric SW MF membranes to determine the influence of the presence of casein in the feed solution on membrane performance. Raw milk was separated at $4^{\circ} \mathrm{C}$, pasteurized at $72^{\circ} \mathrm{C}$ with a holding time of $16 \mathrm{~s}$, cooled, and stored at $4^{\circ} \mathrm{C}$. The pasteurized SM was split into 2 batches. One batch was MF using a pilot-scale ceramic UTP Membralox membrane system (model EP1940GL0.1 $\mu$ A, 0.1- $\mu \mathrm{m}$ alumina; Pall Corp., East Hills, NY) at $50^{\circ} \mathrm{C}$ to produce retentate and permeate. The ceramic MF permeate from UTP, which was the CFSM, was cooled to $4^{\circ} \mathrm{C}$ and stored overnight. On the next day after initial cleaning, the clean water flux was measured and then CFSM was MF using polymeric SW membranes at a concentration factor of $3 \times$ and temperature of $50^{\circ} \mathrm{C}$. The process was carried out for $65 \mathrm{~min}$ in full recirculation (i.e., both retentate and permeate returned to the feed vat) mode. The membrane was flushed with $170 \mathrm{~L}$ of $50^{\circ} \mathrm{C}$ reverse osmosis (RO) water and the fouled membrane water flux was determined. After that, pasteurized SM was immediately 


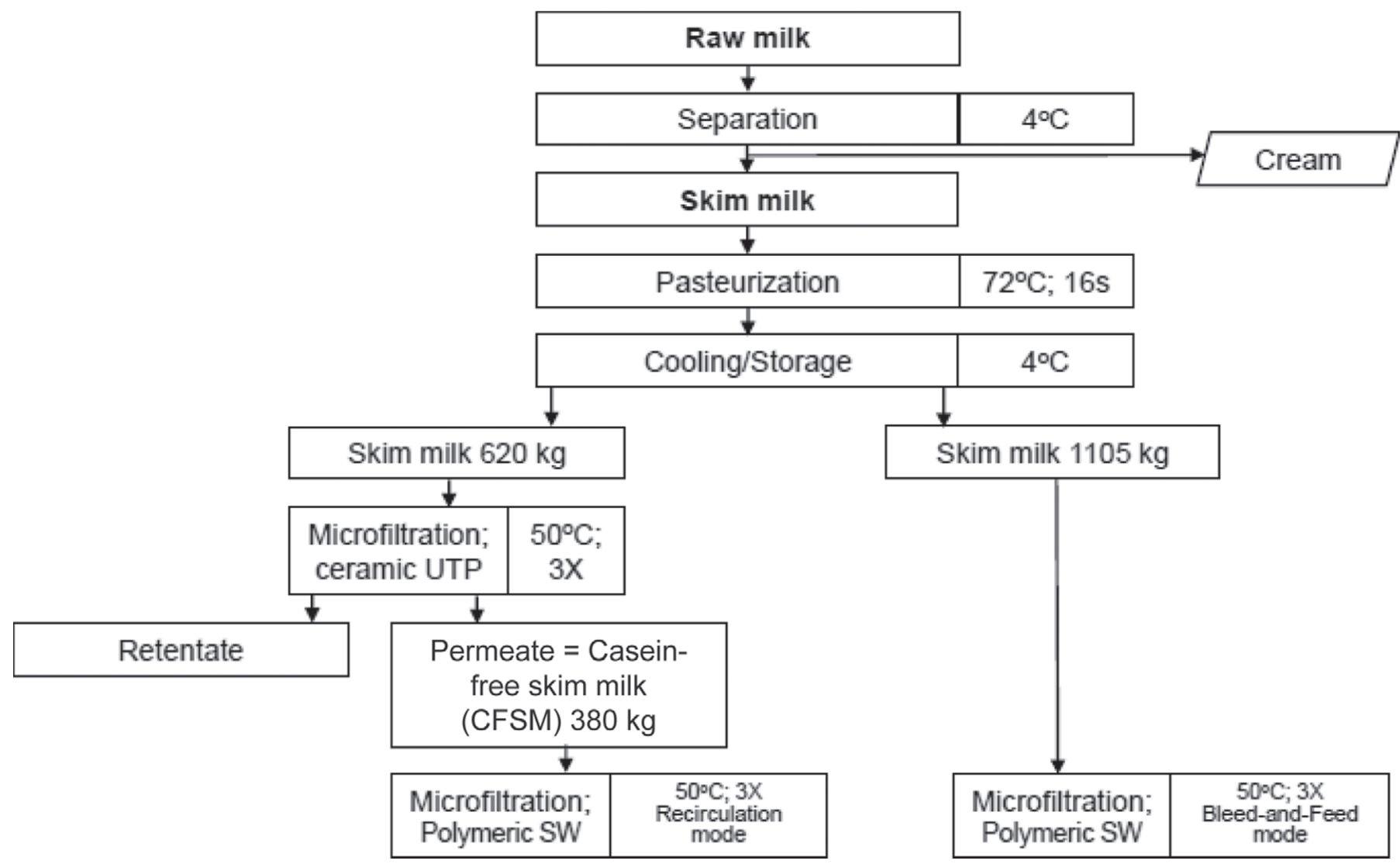

Figure 1. The experimental design of the study. UTP = uniform transmembrane pressure; SW $=$ spiral wound.

$\mathrm{MF}$ at $50^{\circ} \mathrm{C}$ in a continuous bleed-and-feed $3 \times$ process using the same SW membranes as for CFSM. At the end of processing, $170 \mathrm{~L}$ of $50^{\circ} \mathrm{C} \mathrm{RO}$ water was flushed through the system and the fouled membrane water flux was measured. Next, the membrane was cleaned and the clean water flux was determined. The experiment was replicated 3 times. The experimental design of this study is shown in Figure 1.

To determine if significant differences existed when processing SM and CFSM, all data were analyzed by ANOVA using the PROC GLM of SAS (SAS version 8.02, 1999-2001; SAS Institute Inc., Cary, NC). The GLM model for composition, average flux, SP removal, and SP removal rate was as follows: dependent variable $=$ source $(\mathrm{SM}$ or CFSM $)+$ replicate + error. To determine if flux changed with the time of processing run, a split-plot model was used, where dependent variable $=$ replicate + time + time $\times$ replicate + time $\times$ time + error, with time as a continuous variable in the model. The flux measurement for the SW membrane was taken every 10 min during processing. Distortion of the ANOVA by multicollinearity in the model was minimized by centering the time of running using a mathematical transformation (Glantz and Slinker, 2001). Time was transformed as follows: time $=$ running time $-[$ last time - first time)/2]. This transformation made the data set orthogonal with respect to time.

\section{Production of CFSM}

Raw whole milk was separated in the Cornell University dairy plant at $4^{\circ} \mathrm{C}$ using a model 590 Air Tight Centrifuge (DeLaval Co., Chicago, IL). The raw SM was pasteurized $(1,380 \mathrm{~kg} / \mathrm{h})$ with a plate heat exchanger (3 sections, regeneration, heating, and cooling; model 080-S; AGC Engineering, Manassas, VA) at $72^{\circ} \mathrm{C}$ and a holding time of $16 \mathrm{~s}$. The milk was cooled to $4^{\circ} \mathrm{C}$ and stored overnight at $\leq 4^{\circ} \mathrm{C}$. The SM (about $620 \mathrm{~kg}$ ) was heated to $50^{\circ} \mathrm{C}$ with a DeLaval model A3 plate heat exchanger (DeLaval Co.) and MF using a pilotscale UTP MF system (Tetra Alcross MFS-7; Tetra Pak Filtration Systems, Aarhus, Denmark) equipped with ceramic Membralox membranes (pore diameter: $0.1 \mu \mathrm{m}$; surface area: $1.7 \mathrm{~m}^{2}$ ). The MF process was continuous bleed-and-feed at a concentration factor of $3 \times$ with retentate and permeate removal rates of 45 and $90 \mathrm{~L} / \mathrm{h}$, respectively, and a transmembrane pressure (TMP) in the range of 24 to $28 \mathrm{kPa}$ during the 
processing run. A more detailed description of the UTP system and process was provided by Zulewska et al. (2009). The total time of milk processing was about 265 min. The MF permeate (i.e., CFSM) was cooled to $4^{\circ} \mathrm{C}$ and held overnight.

\section{Processing of CFSM and SM}

The CFSM and SM were processed at $50^{\circ} \mathrm{C}$ with polymeric PVDF SW membranes (model FG7838OS0x-S; Parker-Hannifin Corp., Process Advanced Filtration Division, Tell City, IN) with a pore size of about $0.3 \mu \mathrm{m}$ and surface area of $20.5 \mathrm{~m}^{2}$. The diameter of the membrane was $198 \mathrm{~mm}$, the spacer $1.09 \mathrm{~mm}$, and the length of the module $96.5 \mathrm{~cm}$. The membrane was placed in stainless steel housing (length of $1.3 \mathrm{~m}$ ) and was mounted horizontally in the membrane system. The SW MF system consisted of feed pump (model 0; Cherry-Burrell Corp., Little Falls, NY) and retentate recirculation pump (model GHH-30; G \& H Products Corp., Kenosha, WI). A PVDF SW MF system was used for MF of CFSM and SM.

CFSM. Immediately before processing, the PVDF membrane was cleaned using the procedure described by Zulewska et al. (2009). The initial clean membrane water flux was measured only with the feed pump turned on, permeate outlet valve fully open, and retentate bleed valve partially open to keep the retentate pressure inlet $(\mathbf{R p i})$ at $35 \mathrm{kPa}$ with the recirculation loop closed, and the temperature of the water was $25^{\circ} \mathrm{C}$. The clean water flux was calculated based on the weight of permeate collected in $30 \mathrm{~s}$ and the total membrane surface area. The MF system was then drained and ready for processing CFSM. Casein-free SM (about 380 $\mathrm{kg}$ ) was weighed into a vat, heated to $50^{\circ} \mathrm{C}$ using a DeLaval model A3 plate heat exchanger, and MF with a SW membrane in recirculation mode for $65 \mathrm{~min}$.

The SW MF system was started as follows: the feed pump was turned on with the permeate exit valve closed; when CFSM started exiting the retentate outlet, the retentate recirculation loop valve was opened to allow CFSM to fill the recirculation loop. Then, the retentate recirculation pump was turned on and the permeate exit valve was opened slowly to balance the pressures and flows of retentate and permeate to achieve $3 \times$ concentration factor and $\Delta P$ (change in pressure) $<105 \mathrm{kPa}$. This resulted in a recirculation flow $( \pm \mathrm{SD})$ of $275 \pm 2.7 \mathrm{~L} / \mathrm{min}$. From this point, the retentate and permeate were both recycled back into the feed vat and the system was run in a full recycle mode. The flux $\left(\mathrm{kg} / \mathrm{m}^{2}\right.$ per hour) of the membrane was determined every $10 \mathrm{~min}$ as a weight of the permeate collected in $30 \mathrm{~s}$ and samples of permeate and retentate (liquids coming out of the hoses) were taken for analysis using an infrared spectrophotometer [LactoScope Fourier transform infrared (FTIR) analyzer; Delta Instruments BV, Drachten, the Netherlands] to monitor the composition of the retentate and permeate for process control. The concentration factor was calculated based on the weights of retentate and permeate collected in $30 \mathrm{~s}$. The retentate and permeate removal flow rates were adjusted every 10 min to keep the concentration factor at $3 \times$. The average flow of the retentate bleed was $13.1 \pm 3.3 \mathrm{~L} / \mathrm{min}$. The mean Rpi was $147.1 \mathrm{kPa}$ and the mean retentate pressure outlet (Rpo) was 63.5 $\mathrm{kPa}$. The permeate pressure outlet was open to the atmosphere with no restriction, with a back pressure of $0 \mathrm{kPa}$. Samples of final retentate and permeate were taken at the end of the run directly from the outlets.

At the end of processing the CFSM, the MF system was drained and the liquid retentate held up in the MF system was combined with the feed solution, which was weighed and sampled. This was done to check if differences existed in composition between CFSM before and after processing that would mainly result from dilution by water remaining in the system after cleaning the membrane. Next, the system was flushed first with $170 \mathrm{~L}$ of $50^{\circ} \mathrm{C} \mathrm{RO}$ water at Rpi and Rpo of 131 and $61 \mathrm{kPa}$, respectively, with no back pressure on the permeate side and the retentate allowed to go to waste. During the second rinse using $150 \mathrm{~L}$ of $25^{\circ} \mathrm{C}$ RO water, the recirculation pump was turned off and the inlet pressure was reduced to $35 \mathrm{kPa}$ by opening the retentate outlet valve. The fouled membrane water flux $\left(\mathrm{kg} / \mathrm{m}^{2}\right.$ per hour) was calculated based on the weight of permeate collected in $30 \mathrm{~s}$ and the membrane. The MF system was drained and SM was processed next without cleaning the system.

$\boldsymbol{S M}$. The SM $(1,105 \mathrm{~kg})$ was heated to $50^{\circ} \mathrm{C}$ using a DeLaval model A3 plate heat exchanger and MF at $50^{\circ} \mathrm{C}$ in a continuous bleed-and-feed $3 \times$ process. The SW MF system was started as described previously for CFSM. The $\Delta \mathrm{P}$ was kept at $<110 \mathrm{kPa}$ with the recirculation flow at $262 \pm 7.7 \mathrm{~L} / \mathrm{min}$. The average flow of the retentate bleed was $2.9 \pm 1.7 \mathrm{~L} / \mathrm{min}$. The mean Rpi was $150.4 \mathrm{kPa}$ and the mean Rpo was $70.4 \mathrm{kPa}$. The permeate pressure outlet was equal to $0.00 \mathrm{kPa}$. At the end of the MF run, the complete collection of retentate and permeate were each sampled. The average total time of milk processing was about $120 \mathrm{~min}$. The same flushing and rinsing procedure was applied as described previously for CFSM and the fouled membrane water flux $\left(\mathrm{kg} / \mathrm{m}^{2}\right.$ per hour) was measured under the same conditions. Then, the SW MF system was cleaned following the same procedure as described previously by Zulewska et al. (2009). The clean membrane water flux was determined by operating only the feed pump with the permeate outlet fully open and an Rpi of $35 \mathrm{kPa}$ 
adjusted by partially opening the retentate bleed valve at $25^{\circ} \mathrm{C}$ with the recirculation loop closed.

\section{Determination of Percent SP Removal and SP Removal Rate}

The efficiency of removal of SP (\%) from SM was measured in a mass-balance experiment by measuring the weight of SM to be processed and the concentration of SP in the SM. The total weight of SP present in the SM was calculated. The SP removed from the SM was calculated by multiplying the weight of permeate removed during the MF process by the concentration of SP in the permeate. From those values, the total weight of SP removed was calculated. The weight of $\mathrm{SP}$ removed divided by the weight of SP at the beginning multiplied by 100 is the percentage SP reduction achieved by the MF process. For CFSM, SP removal was calculated in a similar way; however, because the processing of CFSM was carried out using a full recirculation process, the weight of permeate that would be produced in 65 min of processing was calculated based on the average concentration factor (calculated every 10 min during processing as a sum of weight of the permeate and retentate collected in $30 \mathrm{~s}$ divided by the weight of retentate collected in $30 \mathrm{~s}$ ).

The SP removal rate $\left(\mathrm{kg} / \mathrm{m}^{2}\right.$ per hour) was calculated as the weight of feed solution (CFSM or SM) processed per meter squared per hour divided by weight of feed solution processed in total and multiplied by the weight of SP removed. The weight of CFSM processed per meter squared per hour was estimated based on the concentration factors $(\mathbf{C F})$ and flux.

\section{Chemical and Instrumental Analyses}

Raw and pasteurized SM (samples taken directly before and after pasteurization, respectively) were analyzed for total N (TN), noncasein N (NCN), and NPN content using Kjeldahl methods of AOAC International (2000; method 991.20, 33.2.11; method 998.05, 33.2.64; and method 991.21, 33.2.12, respectively). Total solids of raw and pasteurized SM were measured using forcedair oven drying (AOAC International, 2000; method 990.20, 33.2.44).

Samples of CFSM, SM, permeate, and retentate from both CFSM and SM collected during processing were analyzed using an infrared spectrophotometer (LactoScope FTIR; Delta Instruments BV) for fat, lactose, and true protein content (Kaylegian et al., 2006). This was done to quickly monitor the composition of retentate and permeate during the run to detect if the system was running normally.
The samples of final retentate and permeate from CFSM and SM were analyzed for TS, TN, NCN, and NPN content using forced-air oven drying (AOAC International, 2000; method 990.20, 33.2.44) and Kjeldahl methods (AOAC International, 2000; method 991.20, 33.2.11; method 998.05; 33.2.64; and method 991.21; 33.2.12 for TN, NCN, and NPN, respectively). Total nitrogen was expressed as $\mathrm{CP}$, and $\mathrm{NCN}$ and NPN results were multiplied by 6.38 . True protein was calculated by subtracting NPN from TN, casein was calculated by subtracting the NCN from TN, and SP content was calculated by subtracting NPN from NCN. All samples were analyzed fresh. The freezing point (Wehr and Frank, 2004) of the feed solution and the final mixture of retentate and permeate was determined to estimate how much water dilution of the feed material occurred at the start in the transition from water to SM or CFSM.

\section{SDS-PAGE Electrophoresis}

To determine the passage of SP through the membrane when processing CFSM and SM, a 10 to $20 \%$ polyacrylamide gradient was used. The fresh samples $(0.1 \mathrm{~mL})$ were diluted with sample buffer $(0.9 \mathrm{~mL})$ that contained $10 \mathrm{mM}$ Tris- $\mathrm{HCl}(\mathrm{pH} 6.8$ ), $1.0 \%$ SDS, $20 \%$ glycerol, $0.02 \%$ bromophenol blue tracking dye, and $50 \mathrm{~m} M$ dithiothreitol, and were stored frozen. Before the analysis, the samples were thawed at room temperature. The diluted samples in glass vials (Target DP Vials C4000-1W; National Scientific Co., Rockwood, TN) sealed with DP Blue Cap (C4000-51B; National Scientific Co.) were heated to $100^{\circ} \mathrm{C}$ in a steam chamber and held for $3 \mathrm{~min}$. The CFSM, permeates, and retentates from CFSM were loaded 35,40 , and $30 \mu \mathrm{L}$, respectively, and SM, permeates, and retentates from SM were loaded $8.5,45$, and $3.5 \mu \mathrm{L}$, respectively, onto an SDS-PAGE gel. The procedure of Verdi et al. (1987) was used for running, staining, and destaining the gels. The gels were scanned with a USB GS 800 Densitometer using Quantity One 1-D Analysis Software (Bio-Rad Laboratories Inc., Hercules, CA) to obtain relative protein proportions within each sample. For a more detailed description of sample analysis, refer to Zulewska et al. (2009).

\section{RESULTS}

\section{Composition of CFSM and Its SW MF Products}

The composition of CFSM was compared with permeate and retentate produced from CFSM (Table 1). By processing SM with ceramic MF UTP membranes it was 
Table 1. Mean ( $\mathrm{n}=3$ ) composition (\% by weight) of the casein-free skim milk (CFSM feed), microfiltration (MF) permeate (CFSM permeate), and MF retentate (CFSM retentate) produced with a $3 \times$ bleed-and-feed process using $0.3-\mu$ m polyvinylidene fluoride spiral-wound (SW) membranes

\begin{tabular}{|c|c|c|c|c|c|c|c|c|}
\hline \multirow[b]{2}{*}{ Item } & \multicolumn{8}{|c|}{ Composition $^{1}$} \\
\hline & $\mathrm{TS}$ & $\mathrm{CP}$ & $\mathrm{NCN}$ & NPN & $\mathrm{TP}$ & Casein & $\mathrm{CN} \% \mathrm{TP}$ & $\begin{array}{c}\text { Serum } \\
\text { proteins }\end{array}$ \\
\hline CFSM feed & $6.47^{\mathrm{a}}$ & $0.76^{\mathrm{b}}$ & $0.74^{\mathrm{b}}$ & $0.18^{\mathrm{a}}$ & $0.57^{\mathrm{b}}$ & $0.020^{\mathrm{b}}$ & $3.48^{\mathrm{b}}$ & $0.55^{\mathrm{b}}$ \\
\hline CFSM permeate & $6.31^{\mathrm{c}}$ & $0.70^{\mathrm{c}}$ & $0.68^{\mathrm{c}}$ & $0.18^{\mathrm{a}}$ & $0.52^{\mathrm{c}}$ & $0.014^{\mathrm{b}}$ & $2.72^{\mathrm{b}}$ & $0.50^{\mathrm{c}}$ \\
\hline CFSM retentate & $6.43^{\mathrm{b}}$ & $0.82^{\mathrm{a}}$ & $0.79^{\mathrm{a}}$ & $0.18^{\mathrm{a}}$ & $0.64^{\mathrm{a}}$ & $0.032^{\mathrm{a}}$ & $4.96^{\mathrm{a}}$ & $0.60^{\mathrm{a}}$ \\
\hline
\end{tabular}

${ }^{\mathrm{a}-\mathrm{c}}$ Means within a column not sharing a common superscript are different $(P<0.05)$.

${ }^{1}$ Crude protein $=$ total $\mathrm{N} \times 6.38 ; \mathrm{NCN}=$ noncasein nitrogen $\times 6.38 ; \mathrm{NPN}=\mathrm{NPN} \times 6.38 ; \mathrm{TP}=$ true protein $(\mathrm{CP}-\mathrm{NPN}) ;$ casein $=\mathrm{CP}-$ $\mathrm{NCN} ; \mathrm{CN} \% \mathrm{TP}=$ casein as percentage of true protein; serum proteins $=\mathrm{TP}-$ casein.

possible to produce UTP permeate (i.e., CFSM feed) containing almost no casein (about $0.020 \%$ ). The casein content of CFSM (Table 1 ) was significantly lower $(P$ $<0.05$; statistical analysis not shown) than that of SM (Table 2). The TS content of both the retentate and permeate were lower than the starting CFSM (Table 1 ). This was due to a small carryover of water (about $1.8 \%$ ) in the MF system at startup of the system, which was estimated from the freezing point (data not shown). The casein content of the MF retentate produced from CFSM was higher $(P<0.05)$ than that of CFSM or CFSM permeate (Table 1), indicating that passage of some of the casein was blocked by the MF membrane. The SP content of MF permeate produced from CFSM (CFSM permeate) was lower $(P<0.05)$ than the CFSM feed and retentate, which indicates some blockage of SP passage through SW polymeric membranes.

\section{Composition of SM and Its SW MF Products}

Composition of SM, permeate, and retentate obtained from SM by processing SM with polymeric
SW membranes is presented in Table 2. Casein was retained in the retentate portion; however, some casein passed through the membrane (i.e., $0.027 \%$ casein in permeate). The SP content was significantly lower $(P$ $<0.05)$ in permeate than in SM and SM retentate. Lower content of SP in SM permeate than in SM would suggest a partial blockage of SP passage through the MF membrane. A small difference $(P<0.05)$ was observed in SP content between CFSM (Table 1) and SM (Table $2 ; 0.55$ vs. $0.58 \%$, respectively); however, direct comparison of SP content between permeates from CFSM and SM (0.50 and $0.33 \%$, respectively) revealed a much larger difference $(P<0.05)$, indicating that passage of SP through the membrane when processing SM was lower than when processing CFSM. We hypothesize that the large difference in casein content between CFSM and SM affected the passage of SP through the membrane. The composition data for SM, SM permeate, and SM retentate are consistent with the data reported by Zulewska et al. (2009) when SM was processed on the same membrane system with the same membrane.

Table 2. Mean ( $\mathrm{n}=3$ ) composition (\% by weight) of the skim milk (SM feed), MF permeate (SM permeate), and MF retentate (SM retentate) produced with a $3 \times$ bleed-and-feed process using $0.3-\mu \mathrm{m}$ polyvinylidene fluoride spiral-wound (SW) membranes

\begin{tabular}{|c|c|c|c|c|c|c|c|c|}
\hline Item & \multicolumn{8}{|c|}{ Composition $^{1}$} \\
\hline SM feed & $9.23^{\mathrm{b}}$ & $3.37^{\mathrm{b}}$ & $0.76^{\mathrm{b}}$ & $0.18^{\mathrm{a}}$ & $3.18^{\mathrm{b}}$ & $2.607^{\mathrm{b}}$ & $81.86^{\mathrm{b}}$ & $0.58^{\mathrm{b}}$ \\
\hline SM permeate & $6.23^{\mathrm{c}}$ & $0.54^{\mathrm{c}}$ & $0.51^{\mathrm{c}}$ & $0.18^{\mathrm{a}}$ & $0.36^{c}$ & $0.027^{\mathrm{c}}$ & $7.42^{\mathrm{c}}$ & $0.33^{\mathrm{c}}$ \\
\hline SM retentate & $13.97^{\mathrm{a}}$ & $7.94^{\mathrm{a}}$ & $1.27^{\mathrm{a}}$ & $0.18^{\mathrm{a}}$ & $7.76^{\mathrm{a}}$ & $6.672^{\mathrm{a}}$ & $86.01^{\mathrm{a}}$ & $1.08^{\mathrm{a}}$ \\
\hline
\end{tabular}

${ }^{\mathrm{a}-\mathrm{c}}$ Means within a column not sharing a common superscript are different $(P<0.05)$.

${ }^{1}$ Crude protein $=$ total $\mathrm{N} \times 6.38 ; \mathrm{NCN}=$ noncasein nitrogen $\times 6.38 ; \mathrm{NPN}=\mathrm{NPN} \times 6.38 ; \mathrm{TP}=$ true protein $(\mathrm{CP}-\mathrm{NPN}) ;$ casein $=(\mathrm{CP}-$ $\mathrm{NCN}) ; \mathrm{CN} \% \mathrm{TP}=$ casein as percentage of true protein; serum proteins $=\mathrm{TP}-$ casein. 
Table 3. Mean $(\mathrm{n}=3)$ water flux after initial cleaning and before processing, after processing casein-free skim milk, after processing skim milk, and after cleaning the membrane for $0.3-\mu \mathrm{m}$ polyvinylidene fluoride spiralwound (SW) membranes postprocessing

\begin{tabular}{|c|c|c|}
\hline Item & $\underset{\left(\mathrm{kg} / \mathrm{m}^{2} \text { per hour }\right)}{\text { Flux }}$ & $\mathrm{SD}$ \\
\hline \multicolumn{3}{|l|}{ Water flux } \\
\hline (1) Water flux before processing & $36.64^{\mathrm{a}}$ & 0.55 \\
\hline (2) Water flux after processing casein-free skim milk & $35.12^{\mathrm{a}}$ & 1.09 \\
\hline (3) Water flux after processing skim milk & $15.19^{\mathrm{b}}$ & 3.42 \\
\hline (4) Water flux after cleaning & $32.90^{\mathrm{a}}$ & 0.63 \\
\hline $\mathrm{R}^{2}$ & 0.98 & \\
\hline SE & 1.09 & \\
\hline
\end{tabular}

\section{Processing}

Water Flux. Water flux was measured at the following points: (1) after initial cleaning and before processing of CFSM, (2) after processing CFSM and before processing SM, (3) after processing SM, and (4) after cleaning the membrane, and are shown in Table 3 . At each measurement, the same procedure was applied: only the feed pump on and recirculation pump off, the permeate outlet fully open, and an Rpi of $35 \mathrm{kPa}$, adjusted by partially opening the retentate bleed valve, the recirculation loop closed, and the water at $25^{\circ} \mathrm{C}$.

No difference $(P>0.05)$ was detected between the fouled water flux $\left(\mathrm{kg} / \mathrm{m}^{2}\right.$ per hour) after processing CFSM and the water flux before processing (35.12 vs. $36.64 \mathrm{~kg} / \mathrm{m}^{2}$ per hour, respectively) the CFSM (Table $3)$. This indicates that no detectable irreversible fouling of the membrane occurred when processing CFSM. However, a significant $(P<0.05) 56.6 \%$ decrease in water flux was observed after processing SM compared with the water flux before SM filtration (15.19 vs. 35.12 $\mathrm{kg} / \mathrm{m}^{2}$ per hour, respectively) as a result of irreversible membrane fouling that occurred during SM processing (Table 3). The cleaning procedure applied after processing was effective and the initial water flux before processing was restored (Table 3$)$. No difference $(P>$ $0.05)$ was detected between water flux before processing and after cleaning ( 36.64 and $32.90 \mathrm{~kg} / \mathrm{m}^{2}$ per hour, respectively). The only major difference in composition between the CFSM (Table 1) and SM feed materials (Table 2) was the casein content. It was concluded that the casein concentration in the feed material made a major contribution to irreversible membrane fouling during the processing of SM with polymeric SW membranes and this fouling changed the solute rejection characteristics of the membrane.

Flux During Processing. During processing of CFSM and SM, the CF were calculated based on the weight of permeate and retentate collected in $30 \mathrm{~s}$. The mean $( \pm \mathrm{SD}) \mathrm{CF}$ were $2.90 \pm 0.01$ and $2.97 \pm 0.05$ for CFSM and SM, respectively. A 4.6-fold higher $(P<$
0.05) average flux $\left(\mathrm{kg} / \mathrm{m}^{2}\right.$ per hour) during processing of CFSM versus SM ( 80.19 vs. $17.22 \mathrm{~kg} / \mathrm{m}^{2}$ per hour, respectively) was detected (Table 4). Given the difference in casein concentration between the CFSM and SM, the difference in flux may be a function of the difference in casein content. Higher casein content in the retentate recirculation loop during processing of SM compared with CFSM (6.67 vs. $0.03 \%$, respectively; Tables 2 and 1 , respectively) caused an increase in viscosity of the recirculating material and this may be related to both lower flux and increased fouling due to viscosity-driven concentration polarization during SM processing.

As shown in Figure 2a, during processing of SM, the largest decrease in flux occurred during the initial 20 min, which accounted for $70 \%$ of the total flux decline over the processing period. The appearance of the MF permeate exiting from the $0.3 \mu \mathrm{m}$ SW PVDF membrane during the first minute of processing was consistently different than the appearance of permeate during the same time period when processing SM using a $0.1-\mu \mathrm{m}$ ceramic UTP or GP membrane. The MF permeate exiting the SW membrane during the first minute looked like SM and then rapidly became clear over the next couple of minutes. This was in contrast to the appearance of MF permeate from ceramic membranes, which was always clear.

After the initial $20 \mathrm{~min}$ of SM processing, the protein content of the retentate reached $7.6 \%$ (Figure 2a),

Table 4. Mean $(\mathrm{n}=3)$ flux during microfiltration of casein-free skim milk and skim milk during processing with a $3 \times$ bleed-and-feed process using $0.3-\mu \mathrm{m}$ polyvinylidene fluoride spiral-wound (SW) membranes

\begin{tabular}{lcc}
\hline Item & $\begin{array}{c}\text { Flux } \\
\left(\mathrm{kg} / \mathrm{m}^{2} \text { per hour }\right)\end{array}$ & $\mathrm{SD}$ \\
\hline Material & $80.19^{\mathrm{a}}$ & 3.12 \\
Casein-free skim milk & $17.22^{\mathrm{b}}$ & 5.21 \\
Skim milk & 0.99 & \\
$\mathrm{R}^{2}$ & 0.54 & \\
$\mathrm{SE}$ & & \\
${ }_{\mathrm{a}, \mathrm{b}}$ Means within a column not sharing a common superscript are dif- \\
ferent $(P<0.05)$.
\end{tabular}



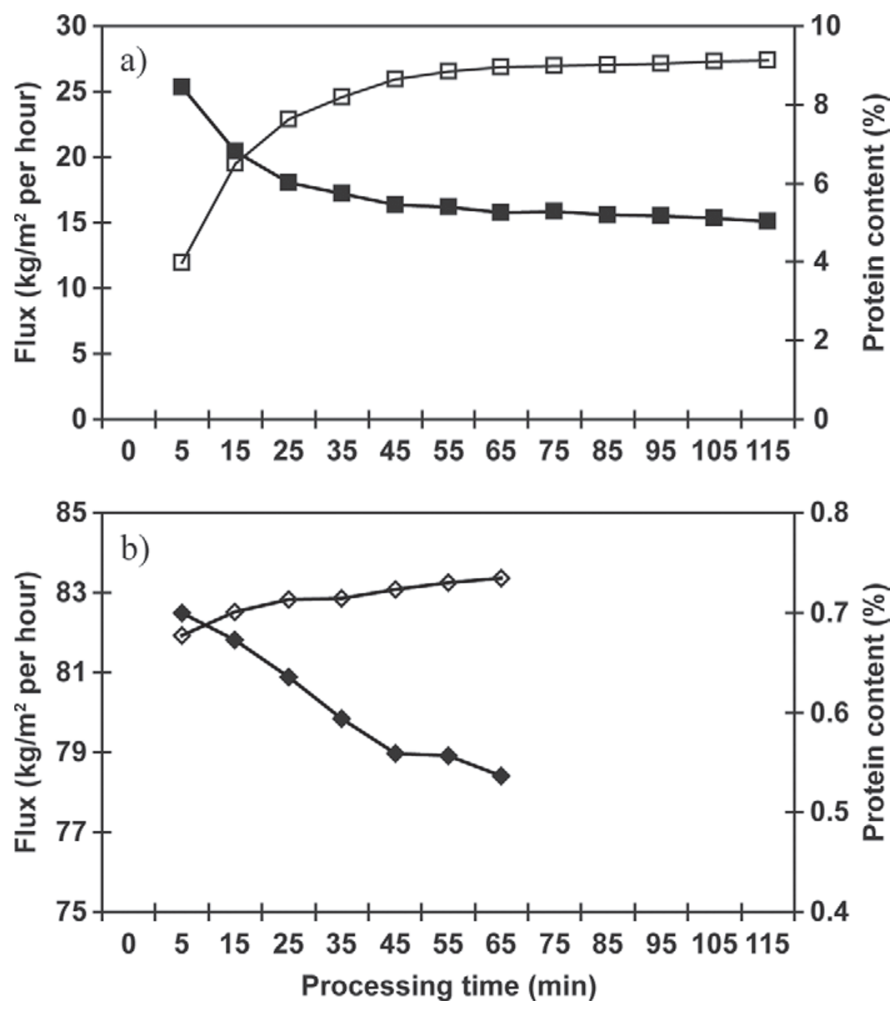

Figure 2. (a) Mean $(\mathrm{n}=3)$ permeate flux $(\mathbf{\square} ; \mathrm{SE}=1.18)$ and true protein content $(\square ; \mathrm{SE}=0.53)$ of retentate produced from skim milk; and $(\mathrm{b})$ mean $(\mathrm{n}=3)$ permeate flux $(\checkmark ; \mathrm{SE}=1.02)$ and true protein $(\diamond ; \mathrm{SE}=0.005)$ content of retentate produced from casein-free skim milk.

which accounted for $71.1 \%$ of the total protein increase, and this corresponds very well with the initial rapid decrease in flux. The gradual increase in protein content in retentate after 20 min relates to a gradual decrease in flux (Figure 2a). Interestingly, for CFSM, a similar trend was observed for increased protein concentration in the retentate and decreased flux (Figure 2b), even if the absolute increase in protein content of the retentate during processing CFSM was small and the flux was much higher than with SM. The protein concentrationrelated decline in flux in both cases may be related to different mechanisms of fouling that may occur with the
2 different feed materials. The flux for SM decreased as a linear and quadratic function (Figure 2a) of time $(P<0.05)$ of processing, whereas flux (Figure $2 \mathrm{~b})$ for CFSM decreased linearly with time $(P<0.05)$. The fouling when processing SM may be concentration polarization driven with cake layer formation, whereas the fouling when processing CFSM may be more a function of pore plugging instead of concentration polarization.

\section{SP Removal}

Theoretical removal of SP in a single-MF stage operating at a $\mathrm{CF}$ of $3 \times$ is $68 \%$, if no rejection of SP occurs by the membrane (Hurt and Barbano, 2010). The CF for CFSM and SM in the present study were 2.90 and $2.97 \times$, respectively. The percentage of SP removal for CFSM was almost twice that of SM (59.5 vs. $35.2 \%$, respectively; Table 5) but approaching the theoretical removal value considering the $\mathrm{CF}$ for the CFSM was 2.9 instead of $3 \times$. With higher flux for CFSM compared with SM, it was possible to remove almost 8 times more SP per unit area in $1 \mathrm{~h}\left(0.40\right.$ vs. $0.05 \mathrm{~kg} / \mathrm{m}^{2}$ per hour, respectively; Table 5). The performance on CFSM indicates that the $0.3-\mu \mathrm{m}$ PVDF SW membrane used in this study at $50^{\circ} \mathrm{C}$ was capable of letting the SP pass through the membrane at levels close to theoretical levels, indicating little rejection of SP by the membrane. The lower flux $(P<0.05)$ with SM than with CFSM (Table 4) and the irreversible decrease in water flux after processing SM (Table 3) indicate that the foulant layer on the SW membrane, not the membrane itself, may be blocking the passage of SP through the membrane when processing SM.

Results of SDS-PAGE analysis of the feed, permeate, and retentate for CFSM and SM are presented as relative percentages of $\beta$-LG and $\alpha$-LA in Table 6 . No difference in the proportion of $\beta-\mathrm{LG}$ and $\alpha-\mathrm{LA}(P>0.05$; Table 6) was detected between CFSM feed and CFSM permeate, which is consistent with little, if any, resistance to passage of SP through the membrane when processing CFSM. Whereas for SM feed the relative percentage of $\beta$-LG and $\alpha$-LA was different than that

Table 5. Serum protein (SP) removal (\%) and SP removal rate $\left(\mathrm{kg} / \mathrm{m}^{2}\right.$ per hour) by $0.3-\mu \mathrm{m}$ polyvinylidene fluoride spiral-wound (SW) membranes from casein-free skim milk and skim milk

\begin{tabular}{lccc}
\hline Item & $\begin{array}{c}\text { Theoretical SP } \\
\text { removal }^{1}(\%)\end{array}$ & $\begin{array}{c}\text { SP removal } \\
(\%)\end{array}$ & $\begin{array}{c}\text { SP removal rate } \\
\left(\mathrm{kg} / \mathrm{m}^{2} \text { per hour }\right)\end{array}$ \\
\hline Feed & & & \\
Casein-free skim milk & 68.0 & $59.46^{\mathrm{a}}$ & $0.40^{\mathrm{a}}$ \\
Skim milk & 68.0 & $35.20^{\mathrm{b}}$ & $0.05^{\mathrm{b}}$ \\
$\mathrm{R}^{2}$ & & $>0.99$ & $>0.99$ \\
$\mathrm{SE}$ & & 0.54 & 0.002 \\
\hline
\end{tabular}

${ }^{\mathrm{a}, \mathrm{b}}$ Means within a column not sharing a common superscript are different $(P<0.05)$.

${ }^{1}$ Assuming no rejection of SP and complete rejection of casein. 
Table 6. Mean $(n=3)$ relative percentage of $\beta-L G$ and $\alpha$-LA for different feeds [casein-free skim milk (CFSM) and skim milk $(\mathrm{SM})]$ and permeate and retentate produced from CFSM and SM with a $3 \times$ bleed-and-feed process using $0.3-\mu \mathrm{m}$ polyvinylidene fluoride spiral-wound (SW) membranes by the densitometric analysis of the SDS-PAGE gels

\begin{tabular}{|c|c|c|c|c|}
\hline \multirow[b]{2}{*}{ Item } & \multicolumn{2}{|c|}{ CFSM } & \multicolumn{2}{|c|}{$\mathrm{SM}$} \\
\hline & $\beta-\mathrm{LG}$ & $\alpha-\mathrm{LA}$ & $\beta-\mathrm{LG}$ & $\alpha-\mathrm{LA}$ \\
\hline \multicolumn{5}{|l|}{ Product } \\
\hline Feed & $76.24^{\mathrm{b}}$ & $23.76^{\mathrm{a}}$ & $80.04^{\mathrm{b}}$ & $19.96^{\mathrm{b}}$ \\
\hline Permeate & $75.71^{\mathrm{b}}$ & $24.29^{\mathrm{a}}$ & $72.35^{\mathrm{c}}$ & $27.65^{\mathrm{a}}$ \\
\hline Retentate & $77.20^{\mathrm{a}}$ & $22.80^{\mathrm{b}}$ & $82.11^{\mathrm{a}}$ & $17.89^{\mathrm{c}}$ \\
\hline $\mathrm{R}^{2}$ & 0.64 & 0.64 & 0.96 & 0.96 \\
\hline \multirow[t]{3}{*}{$\mathrm{SE}$} & 0.26 & 0.26 & $0.56^{1}$ & $0.56^{1}$ \\
\hline & & & $0.50^{2}$ & $0.50^{2}$ \\
\hline & & & $0.45^{3}$ & $0.45^{3}$ \\
\hline
\end{tabular}

${ }^{a-c}$ Means within a column not sharing a common superscript are different $(P<0.05)$.

${ }^{1} \mathrm{SE}$ for SM.

${ }^{2} \mathrm{SE}$ for SM permeate.

${ }^{3} \mathrm{SE}$ for SM retentate.

of SM permeate, the content of $\beta$-LG was lower $(P<$ $0.05)$ in the SM permeate than SM (72.35 vs. $80.04 \%$; Table 6). Higher rejection of $\beta$-LG when processing SM with polymeric SW membranes was reported previously (Lawrence et al., 2008; Zulewska et al., 2009; Beckman et al., 2010). In a previous study, Zulewska et al. (2009) compared the SP passage for 2 ceramic (UTP and GP) and a polymeric PVDF SW membrane (same as used in the current study) and reported significantly lower content of $\beta$-LG in permeate from SW membranes than for permeates from both ceramic UTP and GP membranes (73.28 vs. 76.04 and $76.31 \%$, respectively), concluding that more $\beta$-LG passed through the ceramic membranes than through the polymeric membrane.

\section{DISCUSSION}

\section{Fouling}

Do different types of milk protein contribute differently to membrane fouling? One of the main limitations in application of MF membranes in the dairy industry is fouling. The flux decline as a measure of degree of fouling is related to protein-membrane interactions. Generally, the proteins present in the feed solution subjected to the MF process can participate in one or more of the following membrane fouling phenomena: adsorption, deposition, and concentration polarization (Belfort et al., 1994). These interactions can cause pore constriction (narrowing), pore blockage (plugging), and gel/cake layer formation. When the diameter of a protein is much smaller than the diameter of a membrane pore, then the protein flows into the pore channel, deposits on the pore walls, and as a result, the pore radius becomes narrowed (Belfort et al., 1994). Proteins with a diameter similar to the diameter of the pores are responsible for pore blocking, whereas when the proteins are bigger than most pores, they form deposits or a cake on the upper surface of the membrane (Belfort et al., 1994).

The monomeric molecular weights of the major individual caseins (e.g., $\beta-\mathrm{CN}, \alpha_{s} \mathrm{CN}$, and $\kappa-\mathrm{CN}$ ) in milk are not that different from $\beta-\mathrm{LG}$ and $\alpha-\mathrm{LA}$; however, caseins spontaneously form very large protein aggregates (called casein micelles) during milk synthesis, whereas $\beta$-LG and $\alpha$-LA do not (Fox and McSweeney, 1998). This makes milk relatively unique as feed material when MF is applied to separate casein from SP. Fractionation of proteins with MF membranes is based on the difference in size between casein micelles and SP; however, other factors also influence the separation. The average size of casein micelles is $0.2 \mu \mathrm{m}$, whereas the average size of SP is approximately $0.0036 \mu \mathrm{m}$ (Walstra et al., 1999); the pore size of PVDF membranes used in our study was $0.3 \mu \mathrm{m}$. Thus, the participation of different milk proteins in the membrane fouling process may differ because of the difference in size distribution and other protein characteristics (e.g., charge and hydrophobic character). It is interesting to note the appearance of the MF permeate from a $0.3-\mu \mathrm{m}$ PVDF membrane when starting the system with $\mathrm{SM}$ at $50^{\circ} \mathrm{C}$. During the first minute of processing, the MF permeate from SM is white (i.e., looks like SM) and then it rapidly becomes a clear greenish color. What happened? It is likely that during this initial startup with a $0.3-\mu \mathrm{m}$ PVDF membrane, casein micelles participated in pore constriction or pore blocking due to binding of casein micelles within the pores because the mean pore size of the PVDF membrane used in our study was similar to, or slightly larger than, the mean particle size of casein 
micelles. Once the membrane pore size had been effectively reduced in the first minute of operation with SM, then the fouled membrane started rejecting almost all of the casein micelles and the permeate became clear. The initial decrease in flux from the clean water flux to the initial flux with milk has been attributed in the literature to adsorption and the following slower decrease to the effects of concentration polarization (Tong et al., 1988). According to Mueller and Davis (1996), this is also typical of external fouling behavior that occurs on the surface of PVDF membranes. They observed a decrease in protein transmission using PVDF MF membrane during the transition between internal pore fouling and external cake filtration. Therefore, we could infer that in the presence of casein micelles, external fouling plays an important role in filtration, influencing protein transmission through the membrane.

The casein micelles rejected by the MF membrane form a fouling layer on the surface of the membrane, referred to as the concentration polarization layer, which leads to cake formation. In contrast to casein micelles, SP with much smaller size than the pore size of the MF membrane may be responsible for a minor amount of membrane pore constriction in the case of $0.3-\mu \mathrm{m}$ PVDF membranes. The work of Tong et al. (1988) found that fouling during UF of whole milk resulted from whey proteins, not casein micelles. The role of SP in pore plugging could be quite different in a polymeric UF membrane where the pore size is much smaller (Tong et al., 1988) than MF.

How does protein concentration in the feed solution influence fouling? Regardless of protein type, the protein concentration in the feed solution, and the steady state protein concentration in the MF recirculation loop, is an important factor determining fouling, flux, and SP rejection in MF of milk. Flux decreases exponentially with increasing feed concentration (Cheryan, 1998). In general, as protein concentration in a solution increases, viscosity of the solution (Walstra et al., 1999) and the probability of protein-protein interactions increase. In addition, viscosity as a function of increasing protein concentration for SM versus CFSM would be different because of the difference in the types of proteins present. The starting SM protein in the feed was about $3.18 \%$ true protein (Table 2 ) versus $0.57 \%$ for the CFSM (Table 1), but at these low protein concentrations at $50^{\circ} \mathrm{C}$, the viscosity difference between the 2 feed solutions was relatively small. At steady state in the MF recirculation loop on the retentate side of the membrane while processing SM, the protein concentration had increased to about 9\% (Figure 2a), whereas the protein concentration of the recirculation loop while processing CFSM had only increased to $0.73 \%$ (Figure $2 \mathrm{~b})$. Thus, the viscosity difference of the steady state solution in the recirculation loop for SM versus CFSM was much larger than the difference in viscosity of the original 2 feed materials and this would promote more membrane fouling with the SM feed. Using a stirredcell MF system with polymeric membranes for concentrating BSA solutions, Mueller and Davis (1996) and Tracey and Davis (1994) showed that at low protein concentrations, protein fouling occurred at the mouth of the membrane pores, whereas higher protein concentrations led to a rapid onset of external fouling because the protein aggregates that deposited on the membrane reduced flux and reduced protein passage through the MF membrane. In our work, the protein concentration when starting the MF process for CFSM (Table 1) was much lower than for SM (Table 2) and a large difference in mean flux existed for the 2 feed materials (Table 4), with the flux for SM being much lower. For both SM (Figure 2a) and CFSM (Figure 2b), the flux decreased with increasing processing time and protein concentration during processing but the decreases in flux were greater at higher protein concentrations found in SM.

The CFSM contains almost exclusively SP, whereas the SM contains approximately an 80:20 ratio of casein:SP. Casein is almost completely rejected by the membrane and does not enter the pores, whereas SP are smaller than the membrane pore size and enter the pores. This might lead us to believe that the different types of protein would contribute to fouling of a 0.3$\mu \mathrm{m}$ polymeric membrane in different ways. It would be interesting to measure flux as a function of protein concentration ranging from a protein concentration of 0.5 to $9 \%$ protein for both CFSM and SM. At low protein concentration, the SP might contribute to pore constriction, whereas at high concentration, the SP might form a boundary layer leading to cake formation on the membrane surface. However, the kinetics of the formation of a protein concentration-dependent boundary layer for SP might be very different than for casein micelles. The fact that we did not observe a significant difference between the initial clean membrane water flux and the water flux after processing CFSM (Table 3 ) indicates that any irreversible interaction of protein (i.e., due to pore constriction) with the membrane had very little effect on the hydraulic resistance of the membrane, whereas the large decrease in water flux after processing SM (Table 3) indicates irreversible interaction of protein (probably casein micelles) with the membrane (i.e., because of concentration polarizationdriven cake layer formation). As stated by Mueller and Davis (1996), higher feed concentration is generally recognized as a reason for higher hydraulic resistance and significant flux loss because of the increased amount of protein in the solution that is carried to and fouls the membrane. Feed solutions with higher protein content 
are more likely to form gel layers and concentration polarization-driven cake layers. Additional studies are needed to better understand the separate roles of SP and casein in the fouling of MF membranes and their contribution to fouling of $0.3-\mu \mathrm{m}$ polymeric membranes might be quite different than their relative contribution to fouling of $0.1-\mu \mathrm{m}$ ceramic membranes.

\section{Factors Influencing SP Removal}

The starting concentration of SP in the CFSM (Table 1) and SM (Table 2) were different. Why was there a difference in SP content between the starting CFSM and SM produced from the same original milk? As shown in a previous study (Zulewska et al., 2009), SP removal by ceramic UTP membrane for a $3 \times$ continuous bleed-and-feed system was slightly lower than theoretical removal (about 64 vs. 68\%, respectively). Lower SP content in CFSM (which is a UTP MF permeate) than that of SM may result from partial rejection of SP by UTP membrane, or SP bonding to the casein micelles during production of CFSM by MF. The retention of some SP with the casein micelles may result from chemical associations among some SP and caseins in native casein micelle structure (Jost et al., 1999).

Why was the SP removal rate from CFSM higher than from SM? The percent SP removal from CFSM was slightly lower than the expected theoretical removal ( 59.46 vs. $68 \%$, respectively; Table 5), even though no irreversible fouling of the membrane was detected by change in water flux of the membrane before and after processing CFSM (Table 3). The relative percentage of $\beta-L G$ was slightly increased in the MF retentate (Table 6) produced from CFSM, indicating that some rejection of $\beta$-LG by the membrane occurred but the reason for this is not clear.

The SP removal (i.e., both $\beta$-LG and $\alpha$-LA) from SM was much lower than from CFSM (Table 5); therefore, we assume that the casein present in SM was responsible for faster and more severe membrane fouling and the fouling by casein changed the separation characteristics. Mochizuki and Zydney (1993), using a $0.16-\mu \mathrm{m}$ polyethersulfone membrane, studied sieving characteristics of albumin deposits, and they concluded that BSA deposits can reject significant amounts of macromolecules (i.e., dextran), with rejection increasing with increased molecular weight. The proportion of $\beta$-LG in the SM retentate was increased (Table 6) relative to the SM feed material (82.11 vs. $80.04 \%$, respectively) because of higher resistance to passage of $\beta$-LG than $\alpha$-LA, even though both proteins were partially rejected by the membrane plus foulant. The extent of membrane fouling that occurred during SM processing is shown clearly by the lower flux during
SM processing (Table 4) and the increased hydraulic resistance of the membrane is demonstrated by lower $(P<0.05)$ water flux after SM processing than before SM processing (Table 3). Vetier et al. (1988) suggested that it is the casein micellar deposit on the surface of the MF membrane that acts as a dynamic membrane, causing soluble proteins to be rejected.

Given the large observed change in the appearance of the MF permeate during the first few minutes of processing with the PVDF membrane used in our study, it appears that initially casein micelles passed through the membrane pores (i.e., when permeate looked like SM during the first minutes of processing) and then either binding of casein micelles within the pores or the development of a concentration polarization and cake layer, or a combination of both, changed the rejection characteristics of the membrane for both casein micelles and SP, while increasing the hydraulic resistance. The fouling layer on the polymeric MF membrane acted as a secondary membrane with more selective rejection characteristics than the PVDF membrane itself. The process carried out in the present study was done at $50^{\circ} \mathrm{C}$. Milk temperature influences the proportion of casein that is inside the casein micelle structure versus monomeric casein dissolved in the milk serum phase outside of casein micelles (Walstra, et al. 1999), with lower temperatures favoring more nonmicellar casein and higher viscosity. If the filtration process were carried out at lower temperature (e.g., 20 or $4^{\circ} \mathrm{C}$ ), the status of dissociation of monomeric casein out of the micelles into the milk serum phase in the SM feed solution would be different and this could result in a difference in the amount of passage of both CN and SP into permeate and a difference in flux. Several researchers have reported lower permeate flux when the MF process was carried out at low temperatures (Lawrence et al., 2008; Karasu et al., 2010).

Permeation flux rules the transport of mass to the membrane (convection) and tangential flow velocity drives transport mass of rejected materials back to the fluid bulk (through the wall shear stress; Le Berre and Daufin, 1996). According to Darcy's law, permeation flux is directly proportional to the applied TMP and inversely proportional to the dynamic viscosity of the fluid permeating the membrane and overall hydraulic resistance (Le Berre and Daufin, 1996). In the current experiment, the mechanical strength of the membrane limited the maximum value of the TMP applied \{calculated as [(inlet pressure - retentate recirculation pressure $) / 2]+($ retentate recirculation pressure $)\}$, which could not exceed $105 \mathrm{kPa}$. Higher casein content in the retentate recirculation loop during processing of SM compared with CFSM (6.67 vs. 0.03\%, respectively; Tables 2 and 1, respectively) increased viscosity of the 
recirculating retentate, which caused lower permeate flux for SM (consistent with Darcy's law). However, several studies showed that increasing TMP can actually cause an increase in rejection of total protein (Kuo and Cheryan, 1983; Lawrence et al., 2008). Lawrence et al. (2008), in an experiment with a PVDF MF membrane, processed SM at different TMP $(50,100,150$, and $258 \mathrm{kPa}$ ) and they concluded that rejection of SP is higher at high TMP. The highest membrane selectivity reported by Lawrence et al. (2008) between SP and casein was achieved at the lowest TMP $(50 \mathrm{kPa})$. Similar findings were reported by Kuo and Cheryan (1983) in a study with a polymeric SW UF membrane when processing cottage cheese whey. Gésan-Guiziou et al. (1999) suggested that high TMP increases compaction of the fouled layer on the membrane surface, thus increasing rejection of proteins. The limiting flux is the value where the flux becomes independent of driving force (Aimar and Field, 1992), obtained when high TMP are applied. The limiting flux depends on crossflow velocity, temperature, feed suspension properties, and geometry of the membrane module (Samulesson et al., 1997). The cross-flow velocity of only $0.19 \mathrm{~m} / \mathrm{s}$ was measured for the SW system used in our study. At this cross-flow velocity, a limiting flux of $1.24 \mathrm{~L} /$ $\mathrm{m}^{2}$ per hour was calculated for the SW system used in our study, which is very low compared with 87 and $96 \mathrm{~L} / \mathrm{m}^{2}$ per hour for ceramic UTP calculated from data of Hurt et al. (2010) and GP calculated from data of Zulewska et al. (2009). In general, polymeric SW membranes work under much lower cross-flow velocities than ceramic tubular membranes (e.g., 5 to $7 \mathrm{~m} / \mathrm{s}$ ).

To achieve optimal performance during MF, a low TMP is required across the entire membrane. It might be better to operate at lower TMP when processing SM with a polymeric SW membrane system to achieve higher average flux during long processing runs and better membrane selectivity to promote higher SP removal.

The performance of polymeric membrane systems is greatly affected by the deposited protein layer that rapidly forms on the membrane surface. By changing the process parameters (i.e., operating at low TMP and high cross-flow velocity) the effect of this protein layer can be minimized (Lawrence et al., 2008). In ceramic membrane systems, high cross-flow velocities (around 7 $\mathrm{m} / \mathrm{s}$ ) are used to minimize the concentration polarization layer by increasing wall shear stress. For tubular ceramic membranes the wall shear stress can be directly calculated from the cross-flow velocity. To create a turbulent flow and limit concentration polarization, an open mesh spacer is placed between the membrane sheets in SW systems. However, for this system, the wall shear stress cannot be directly calculated from the cross-flow velocity (Lawrence et al., 2008). The wall shear stress values of only 0 to $5 \mathrm{~Pa}$ were reported (Schwinge et al., 2002) for systems with multiple spacer filaments and this is significantly lower than calculated values for ceramic MF systems (123 and $146 \mathrm{~Pa}$ for UTP and GP systems, respectively) used in our studies (Hurt et al., 2010; Zulewska et al., 2009). It is worth noting that the spacers in polymeric systems are really eddy promoters more than turbulence promoters (Schwinge et al., 2004).

\section{CONCLUSIONS}

Little resistance occurred to passage of milk SP through a $0.3-\mu \mathrm{m}$ PVDF SW membrane at $50^{\circ} \mathrm{C}$ and no detectable increase in hydraulic resistance of the membrane when processing CFSM. Therefore, milk SP contributed little, if any, to fouling of the PVDF membrane. In contrast, when processing SM containing a normal concentration of casein, the flux was much lower than when processing CFSM (17.2 vs. $80.2 \mathrm{~kg} /$ $\mathrm{m}^{2}$ per hour, respectively) and the removal of SP from SM with a single-pass $3 \times$ bleed-and-feed MF system was also much lower than from casein-free SM (35.2 vs. $59.5 \%$ removal, respectively). Thus, when processing SM with a PVDF SW membrane, casein was the major protein foulant that increased hydraulic resistance and reduced passage of SP through the membrane.

\section{ACKNOWLEDGMENTS}

The authors thank the Northeast Dairy Foods Research Center (Ithaca, NY) and the New York State Milk Promotion Board for partial funding of this research. The technical assistance of the following Cornell University staff members is greatly appreciated: Mark Newbold, Maureen Chapman, Chassidy Coon, Jessica Mallozzi, and Karen Wojciechowski.

\section{REFERENCES}

Aimar, P., and R. Field. 1992. Limiting flux in membrane separations: A model based on the viscosity dependency of the mass transfer coefficient. Chem. Eng. Sci. 47:579-586.

Aimar, P., and V. Sanchez. 1986. A novel approach to transfer-limiting phenomena during ultrafiltration of macromolecules. Ind. Eng. Chem. Fundam. 25:789-798.

Altmann, J., and S. Ripperger. 1997. Particle deposition and layer formation at the crossflow microfiltration. J. Membr. Sci. 124:119 128

AOAC International. 2000. Official Methods of Analysis. 17th ed. AOAC International, Gaithersburg, MD.

Baruah, G. L., A. Nayak, and G. Belfort. 2006. Scale-up from laboratory microfiltration to a ceramic pilot plant: Design and performance. J. Membr. Sci. 274:56-63.

Beckman, S. L., J. Zulewska, M. Newbold, and D. M. Barbano. 2010. Production efficiency of micellar casein concentrate using polymeric spiral-wound microfiltration membranes. J. Dairy Sci. 93:4506-4517. 
Belfort, G., R. H. Davis, and A. L. Zydney. 1994. The behavior of suspensions and macromolecular solutions in cross-flow microfiltration. J. Membr. Sci. 96:1-58.

Brans, G., C. G. P. H. Schroën, R. G. M. van der Sman, and R. M. Boom. 2004. Membrane fractionation of milk: State of the art and challenges. J. Membr. Sci. 243:263-272.

Cheryan, M. 1998. Chapter 4: Performance and engineering models. Pages 136-137 in Ultrafiltration and Microfiltration Handbook. Technomic Publishing Company Inc., Lancaster, PA.

Fox, P. F., and P. L. H. McSweeney. 1998. Page 150 in Dairy Chemistry and Biochemistry. Blackie Academic \& Professional, London, UK

Gésan-Guiziou, G., E. Boyaval, and G. Daufin. 1999. Critical stability conditions in crossflow microfiltration of skimmed milk: Transition to irreversible deposition. J. Membr. Sci. 158:211-222.

Glantz, S. A., and B. K. Slinker. 2001. Multicollinearity and what to do about it. Pages 185-187 in Primer of Applied Regression \& Analysis of Variance. 2nd ed. McGraw-Hill Inc. New York, NY.

Güell, C., and R. H. Davis. 1996. Membrane fouling during microfiltration of protein mixtures. J. Membr. Sci. 119:269-284.

Huisman, I. H., P. Prádanos, and A. Hernández. 2000. The effect of protein-protein and protein-membrane interactions on membrane fouling in ultrafiltration. J. Membr. Sci. 179:79-90.

Huisman, I. H., and C. Trägårdh. 1999. Particle transport in crossflow microfiltration-I. Effects of hydrodynamics and diffusion. Chem. Eng. Sci. 54:271-280.

Hurt, E., and D. M. Barbano. 2010. Processing factors that influence casein and serum protein separation by microfiltration. J. Dairy Sci. 93:4928-4941.

Hurt, E., J. Zulewska, M. Newbold, and D. M. Barbano. 2010. Micellar casein concentrate production with a $3 \times, 3$-stage, uniform transmembrane pressure ceramic membrane process at $50^{\circ} \mathrm{C}$. J. Dairy Sci. 93:5588-5600

James, B. J., Y. Jing, and X. D. Chen. 2003. Membrane fouling during filtration of milk-A microstructural study. J. Food Eng. 60:431-437.

Jost, R., R. Brandsma, and S. Rizvi. 1999. Protein composition of micellar casein obtained by cross-flow microfiltration of skimmed milk. Int. Dairy J. 9:389-390.

Karasu, K., N. Glennon, N. D. Lawrence, G. Stevens, A. J. O'Connor, A. R. Barber, S. Yoshikawa, and S. E. Kentish. 2010. A comparison between ceramic and polymeric membrane systems for casein concentrate manufacture. Int. J. Dairy Technol. 63:284-289.

Kaylegian, K. E., G. E. Houghton, J. M. Lynch, J. R. Fleming, and D. M. Barbano. 2006. Calibration of infrared milk analyzers: Modified milk versus producer milk. J. Dairy Sci. 89:2817-2832.

Kelly, S. T., W. Senyo Opong, and A. L. Zydney. 1993. The influence of protein aggregates on the fouling of microfiltration membranes during stirred cell filtration. J. Membr. Sci. 80:175-187.

Kelly, S. T., and A. L. Zydney. 1995. Mechanisms for BSA fouling during microfiltration. J. Membr. Sci. 107:115-127.

Kelly, S. T., and A. L. Zydney. 1997. Protein fouling during microfiltration: Comparative behavior of different model proteins. Biotechnol. Bioeng. 55:91-100.

Kuo, K.-P., and M. Cheryan. 1983. Ultrafiltration of acid whey in a spiral-wound unit: Effect of operating parameters on membrane fouling. J. Food Sci. 48:1113-1118.

Lawrence, N. D., S. E. Kentish, A. J. O'Connor, A. R. Barber, and G. W. Stevens. 2008. Microfiltration of skim milk using polymeric membranes for casein manufacture. Separ. Purif. Tech. 60:237244.

Le Berre, O., and G. Daufin. 1996. Skimmilk crossflow microfiltration performance versus permeation flux to wall shear stress ratio. J. Membr. Sci. 117:261-270.
Marcelo, P. A., and S. S. H. Rizvi. 2009. Applications of Membrane Technology in the Dairy Industry. Page 651 in Handbook of Membrane Separations: Chemical, Pharmaceutical, Food and Biotechnological Applications. A. K. Pabby, S. S. H. Rizvi, and A. M. Sastre, ed. CRC Press, New York, NY.

Marshall, A. D., P. A. Munro, and G. Trägårdh. 1993. The effect of protein fouling in microfiltration and ultrafiltration on permeate flux, protein retention and selectivity: A literature review. Desalination 91:65-108.

Meireles, M., P. Aimar, and V. Sanchez. 1991. Albumin denaturation during ultrafiltration: Effects of operating conditions and consequences on membrane fouling. Biotechnol. Bioeng. 38:528-534.

Mochizuki, S., and A. L. Zydney. 1993. Sieving characteristics of albumin deposits formed during microfiltration. J. Colloid Interface Sci. 158:136-145.

Mueller, J., and R. H. Davis. 1996. Protein fouling of surface-modified polymeric microfiltration membranes. J. Membr. Sci. 116:47-60.

Reihanian, H., C. R. Robertson, and A. S. Michaels. 1983. Mechanisms of polarization and fouling of ultrafiltration membranes by proteins. J. Membr. Sci. 16:237-258.

Samulesson, G., I. H. Huisman, G. Trägårdh, and M. Paulsson. 1997. Predicting limiting flux of skim milk in crossflow microfiltration. J. Membr. Sci. 129:277-281.

Schwinge, J., P. R. Neal, D. E. Wiley, D. F. Fletcher, and A. G. Fane. 2004. Spiral wound modules and spacers-Review and analysis. J. Membr. Sci. 242:129-153.

Schwinge, J., D. E. Wiley, and D. F. Fletcher. 2002. Simulation of the flow around spacer filaments between narrow channel walls. 1. Hydrodynamics. Ind. Eng. Chem. Res. 41:2977-2987.

Tong, P. S., D. M. Barbano, and M. A. Rudan. 1988. Characterization of proteinaceous membrane foulants and flux decline during the early stages of whole milk ultrafiltration. J. Dairy Sci. 71:604-612.

Tracey, E. M., and R. H. Davis. 1994. Protein fouling of track-etched polycarbonate microfiltration membranes. J. Colloid Interface Sci. 167:104-116.

van der Horst, H. C. 1995. Fouling of organic membranes during processing of dairy liquids. Pages 37-52 in Fouling and Cleaning of Pressure Driven Membrane Processes. IDF Special Issue 9504. International Dairy Federation (IDF), Brussels, Belgium.

van der Meer, W. G. J., and J. C. van Dijk. 1997. Theoretical optimization of spiral-wound and capillary nanofiltration modules. Desalination 113:129-146.

Verdi, R. J., D. M. Barbano, M. E. Dellavalle, and D. F. Senyk. 1987. Variability in true protein, casein, nonprotein nitrogen, and proteolysis in high and low somatic cell count milks. J. Dairy Sci. $70: 230-242$.

Vetier, C., M. Bennasar, and B. Tarodo de la Fuente. 1988. Study of the fouling of a mineral microfiltration membrane using scanning electron microscopy and physicochemical analysis in the processing of milk. J. Dairy Res. 55:381-400.

Walstra, P., T. J. Geurts, A. Noomen, A. Jellema, and M. A. J. S. van Boekel. 1999. Dairy Technology: Principles of Milk Properties and Processes. Marcel Dekker Inc., New York, NY.

Wehr, H. M., and J. F. Frank. 2004. Chapter 15.032 in Standard Methods for the Examination of Dairy Products. 17th ed. American Public Health Assoc., Washington, DC.

Zulewska, J., M. W. Newbold, and D. M. Barbano. 2009. Efficiency of serum proteins removal from skim milk with ceramic and polymeric membranes at $50^{\circ}$ C. J. Dairy Sci. 92:1361-1377. 